\title{
PUBLICIDAD Y ÉTICA
}

Carlos de la Isla*

\section{Enormes anuncios espectaculares}

atrapan al transeúnte de todas las direcciones. Aquí un brillante coche acariciado por una bella dama que invita a manejarlo en su compañía; después el paisaje encantador de la campiña, del bosque abundante, de los manantiales de agua cristalina y en primer plano los caballos salvajes, poderosos, domados y montados por jinetes de hermosa rudeza aspirando el refrigerio del cigarro irresistible. Inmediatamente detrás, la exposición de cuerpos enteros de humanos, hombres y mujeres mostrando el modelo mínimo de ropa interior; luego las caras de colores intensos, de pestañas postizas, con labios de humedad postiza, de pómulos y de mentón de cirugía voluble anunciando el cosmético, la ropa y la tienda que construyen personalidades arrolladoras. Y por todas partes refrescos, vinos y cervezas, balones, bancos milagrosos, y otra vez carne, abundante carne, esta vez de las mejores reses para las hamburguesas trasnacionales. Todos los anuncios se proyectan en tal perspectiva que producen el efecto de un lanzamiento sobre los transeúntes que resultan atrapados por tantas tentaciones.

Los anuncios publicitarios han invadido todos los espacios. Allí, donde la mirada oprimida busca libertad, inmediatamente se planta el muro publicitario. Ya no es posible contemplar los volcanes, las colinas arboladas o la infinidad azul del cielo. Estamos inmersos en el pozo de las provocaciones.

La finalidad es la misma, la técnica es diferente. Las revistas están tan plagadas de placas publicitarias que con frecuencia el lector se

* Departamento Académico de Estudios Generales, ITAM. 
convierte en buscador del texto colocado en los resquicios que dejan las tintas fuertes de las caras y escenas impresionantes de los anuncios.

Los diarios periódicos amasan enormes fortunas con la venta de páginas enteras o mitades, cuartos u octavos anunciando todo, absolutamente todo de acuerdo al mejor postor. Con frecuencia tiran o regalan miles de ejemplares para 'justificar', por el alto tiraje, los subidos precios de los anuncios.

Y ¿qué decir de la publicidad en la TV? ¿Quién no se harta de la inverosímil cantidad de anuncios en todos los programas, de todas las cantidades y cualidades, con cortes estudiados para captar la atención e interés de los oyentes y videntes?

Las emisoras son muy conscientes del fastidio que causan sus inserciones mercantiles y de que los televidentes mantienen empuñado el control remoto para buscar otro programa mientras están presentes los patrocinadores. Para evitar estas fugas o bien, para obligar a digerir los comerciales, establecen acuerdos, por encima de toda competencia, sobre los tiempos más importantes, los tiempos que arrojan dinero. Lograda esta sincronía todo cambio de canal se reduce a transitar de uno a otro anuncio publicitario.

La publicidad en los cines maneja estrategias singulares: Los productos anunciados recorren largas y vertiginosas velocidades desde las penumbras lejanas hasta los primeros planos que golpean. El objeto que debe ser consumido debe penetrar la vista, el oído, el tacto, el gusto. La fuerza del lanzamiento es brutal. El sonido es estridente, más allá de toda percepción. El colorido deslumbrante simplemente distorsiona las formas y rompe toda unidad de dimensiones. Se produce un caos estudiado y compacto para introducir en el desorden de lo visible lo que debe ser visto, gustado y consumido.

Está prohibida la publicidad subliminal, pero es absolutamente falso que no exista. Entre imagen e imagen, entre sonido y sonido, entre impresión e impresión se alojan visiones y presiones imperceptibles lanzadas hasta la zona obscura de la conciencia, y allí actúan con fuerza irresistible para desatar la acción consumidora. 
La inmoralidad del procedimiento subliminal radica en que con plena intención los mercaderes penetran el apetito y la voluntad e imponen los deseos y la 'necesidad' del objeto, introducido imperceptiblemente. El ocultamiento de los móviles que producen la elección convierten a la persona literalmente en una marioneta movida por los hilos invisibles. El acto humano implica el pleno conocimiento que permite un juicio valorativo para que la decisión sea consciente y libre. Si el objeto que se presenta no llega a ser percibido por la conciencia, tampoco podrá ser juzgado, apreciado y libremente elegido. En esto consiste la inmoral dictadura del mercado que mutila a la persona para convertirla en comprador de cosas. Es el vaciamiento del yo para dar lugar al relleno del mercado.

Sin embargo, la exacerbada discusión sobre la existencia de factores subliminales, en el fondo es estéril, porque en la publicidad abierta, en la común y constante los factores que manejan son visibles, evidentes; lo que permanece oculto es el tejido innumerable de tensiones, urgencias y presiones combinadas que conducen a la acción determinada del consumo inevitable.

En Praga, ciudad que ha petrificado la historia convertida en magia, existe un espectáculo maravilloso de marionetas: fantásticos personajes de ópera, directores de orquesta, músicos, payasos y bufones despliegan magnífica actuación. Lo singular en este teatro es que en la altura se pueden ver las enormes manos que manejan a esos personajes. Manos fuertes y muy diestras producen los movimientos más sutiles y perfectos; juegan con las piernas y los brazos para el baile, abren y cierran las bocas en los cantos de sopranos y tenores, trazan muecas, gestos, caravanas... excelente obra de arte y magníficos manejadores los que la producen.

Lo que no se ve en ese ensueño de las marionetas es el tinglado, los alambres y resortes, los trapecios, las bisagras y los goznes que conectan las grandes manos con las graciosas marionetas. En la publicidad subliminal no se aprecian ni las manos ni los hilos. En la otra publicidad se ven claramente las manos que manejan, pero permane- 
cen invisibles los mecanismos usados para orquestar el movimiento y las pulsiones del consumo imperativo.

Algunos ejemplos: Millones de jóvenes contemporáneos que pertenecen a la generación ' $\mathrm{X}$ ' (sin definición, sin atributos, sin colorido ni aspiraciones propias) se sienten acosados por un pasado de barbarie, por un presente de insensatez globalizada, se ven amenazados por un futuro de turbulencias. La generación $X$ vive a la deriva, sufre de incertidumbre, necesita seguridad; por eso se refugia en la masa y adopta sus modales y costumbres.

Los mercaderes aprovechan la actitud de rechazo a los adultos y la docilidad de todos para seguir los movimientos de las multitudes. Así producen la moda de protesta: rompimiento total de todo lo establecido. El hombre se cuelga aretes (antes distintivos de mujeres), sortijas en la nariz en las cejas o en los labios. Las mujeres muestran el ombligo con pantalones resbaladizos y caídos. Ellos y ellas se pintan el pelo con los colores más chillones y exóticos: amarillo hiriente, violeta, rojo sangre... Cuando el pantalón de mezclilla (uniformador de sexos y naciones) parecía amenazado en el mercado, aparece de nuevo y se impone desgarrado, desteñido, ensuciado y repugnante, y vuelve a reinar por la orden de los dictadores de la moda que se gozan en reírse y burlarse de las masas con sus patológicas imposiciones. Son conscientes estos dictadores de que pueden mofarse de toda norma de estética y de pudor elemental y de que pueden revestir a los infinitos rebaños con las más grotescas cubiertas. Es tal la sumisión de los rebaños y el poder de sus conductores que cualquiera que no siga las prescripciones de vestidos, semi y mini vestidos, de zapatos altos, delgados o chatos, de cosméticos para el arreglo y el desarreglo... será castigada con el vacío de una sociedad obediente al estilo de 'clase'.

Y los arquitectos de las líneas que cubren los cuerpos y los descubren son expertos en acelerar la rápida caducidad de las prendas poniendo cuidado en que las modificaciones sean violentas para poner en ridículo a todos los que no se apresuren al cambio. Así pasan de la falda larga a la casi imperceptible minifalda; de la tela gruesa y áspera a la seda casi transparente que precisa la entera anatomía; de los zapatos 
de tacón largo, fino y agudo pasan a la plataforma pesada construida a escala del modelo de un tanque de guerra. Pasan de la armonía de colores en la ropa, en la piel y en las mejillas a los tonos estridentes más exóticos y exuberantes. Pasan de las modas y modales muy masculinos para los hombres y muy femeninos para las mujeres al acercamiento total unisex o a la total inversión.

Los seguidores de la gran masa, porque en ella encuentran seguridad, corren con la corriente y obedecen incondicionalmente las leyes de la moda y a sus dictadores. Otro resorte invisible aprovechado por las grandes manos que mueven las marionetas es la insatisfacción unida a la necesidad de aceptación social.

Se ha calificado esta generación como egoísta y de insaciable hedonismo. La felicidad entendida como el estado de equilibrio que se da por la satisfacción de los deseos se hace imposible en esta sociedad de mercado, porque la publicidad se encarga de romper cualquier expresión de saciedad por la creación de infinitos deseos. Las personas contentas con lo que tienen, porque lo que tienen es suficiente para esa cierta plenitud, son enemigos del mercado.

Si la publicidad crea tantos y tales deseos que no pueden ser satisfechos se puede concluir que la publicidad hace hombres insatisfechos e infelices. El grado de infelicidad se mide por el grado de deseos y aspiraciones insatisfechos, y como el hombre de todas las edades tiende a recuperar el equilibrio (homeostasis lo llaman los psicólogos) que da felicidad entonces se lanzan las multitudes insatisfechas con verdadero frenesí a conseguir los satisfactores de sus 'necesidades'. Allí, otra vez la publicidad se comporta como una ofrecida servidora y pone a las puertas de la fantasía los más encantadores objetos de satisfacción. Es la portadora de la 'felicidad'. Por supuesto que la misma obsequiosa sirvienta se encargará de romper ese equilibrio al crear nuevos deseos con rostro de necesidades para desatar la furia por la satisfacción, y así hasta el infinito del mercado interminable.

Hay que decir que en todo este proceso hay tramos de repugnante crueldad. La publicidad indiferenciada en todos crea deseos que rompen la homeostasis, a todos presenta los satisfactores de sus necesidades, 
pero son poquísimos los que pueden adquirirlos. La operación es evidente productora de insatisfechos, de infelices, de conscientes víctimas de las armas del mercado.

Además, este sistema es generador de odios que incendian la violencia. ¿Por qué tan pocos pueden hartarse de 'felicidad' y tantos, tantos millones quedan sumidos en la angustia y en la desesperación? La insensatez se acentúa si evaluamos la eterna insatisfacción de los obsesionados por comprar felicidad obedeciendo las prescripciones de la publicidad.

En la apología del capitalismo se exalta al hombre inconforme que aspira siempre a más y nunca se siente contento con lo que tiene. Éstos son los hombres que generan riqueza, dicen. La continua superación es muy laudable si se extiende a todas las dimensiones de la persona. Pero la inconformidad e ilimitada superación del capitalismo son unidimensionales. Sólo aparecen en el ámbito de las tenencias, de las posesiones materializadas.

Según el PNUD las riquezas de los tres hombres más ricos del mundo (ídolos de nuestro sistema) equivalen al PIB de las 48 naciones más pobres. Sería excesivo decir que los hombres ricos son la causa de

12 toda la pobreza en el mundo y de todos las muertes por hambre, pero por el solo hecho de poner el dinero por encima de las personas, de considerar al hombre como mercancía, de explotar la mano de obra barata, de lograr la eficiencia y la eficacia empresarial a costa del desempleo y de la humillación de los trabajadores... ciertamente se establece una evidente complicidad, dice la ética. La publicidad es el instrumento para las grandes ventas y ganancias; así se construyen los grandes consorcios, las cadenas trasnacionales y multinacionales. Éstas poseen los infinitos capitales para alimentar sus agencias publicitarias que, a su vez, presionan las compras internacionales, así se cierra el círculo del imperialismo económico que absorbe las economías domésticas.

Rius, el filósofo social de las caricaturas, traza una ligera ruta trasnacional que muchos mexicanos atrapados por la publicidad recorren cada día dentro de su propia casa: 
Primero, levantarse de un box spring Selther, Springair, Simmons o Sealy; después, calentar Nescafé o Decaf en una estufa Mabe o Delher; usar un retrete Stanford, lavarse la boca con Colgate, Oral B, Crest o Isodine, bañarse bajo una regadera Helvex con shampoo Folicure, Pantene, Caprice o Head and Shoulders y jabonarse con Safegard, Palmolive, Heno de Pravia, Dove o Zest.

Los hombres, rasurarse con Gillete, aplicarse desodorante Brut, Adidas o Patrichs y ponerse loción (la que sea es extranjera). Las mujeres, maquillarse con Revlon, L'Oreal, Maybelline o, de perdida, Zan Zusi.

Y a la hora de vestirse, si se trata de ropa de mezclilla, primero hay que ponerse los calcetines Donelly o las medias Dorian Gray, Carla Conti o Forever, para después enfundarse calzones Rimbros, una modesta camiseta Zaga, un Levis, un Lee, un Guess y la camisa Polo, Arrow, Saint Laurent, Aca Joe o la que se quiera.

¿Desayunar? Si la prisa impone un empanzonador licuado, órale con las licuadoras General Electric, Osterizer o Hamilton Beach para lo cual hay que sacar del refri Westinghouse los insumos necesarios. Ni se diga cuando se quiere un plato de Corn Flakes con plátanos importados de Guatemala o de Honduras que plagan inclusive los mercados rurales.

A la hora de la comida la sopa requiere Knorr Suiza y casi nada que se quiera de platillo fuerte escapa de la lista que puede surtirse en Wal Mart o en Home Mart. Para los niños que van a la escuela tengan Scribe, sus lápices Mirado y sus lapiceros Bic (porque no saben fallar), calzados con Nike, Reebok y chamarras gringas.

Ninguna marca automotriz -pero tampoco siquiera de bicicletases Benítez, Jiménez o Godínez. Y por la noche (si se está por encima del consumo de velas de cera o de cebo) a encender focos Osram o Phillips y ni se diga la Sony Trinitron, la Panasonic o la Samsung.

Hasta aquí la ruta trasnacional que Rius describe hace más de cuarenta años. Se puede prolongar muchísimos kilómetros más; hacia los bancos, por ejemplo: BBVA, Scotia Bank, City Group, Bank of America, Santander, Honk Kong... Si se trata de hoteles: Sheraton, Four Seasons, 
Westin, Melia, Niko, Fiesta... Si se apetece un restaurant: Sofía, Alfredo's, Carlos and Charlie's, La costa vasca, Vips, Mc Donald's...

La publicidad es el arma necesaria e infalible del imperialismo internacional de las trasnacionales. ¿Quién podrá combatir y dominar la hidra de cien mil cabezas? Se instalan con soportes multimillonarios en los lotes más codiciados de las naciones pobres. Muchas veces reciben financiamiento de los bancos locales por sus créditos ilimitados. Compran mano de obra barata y productos muy rebajados por las inmensas cantidades que adquieren. Pueden vender a precios muy bajos para ahogar a la competencia, y una vez que son dueñas del mercado imponen la discrecionalidad de sus etiquetas continuamente cambiantes a la alza. Invierten enormes cantidades en publicidad especializada hasta seducir los gustos y preferencias de los consumidores. Y así se adueñan de los capitales y de las voluntades estas compañías trasnacionales y multinacionales que son los terribles tentáculos del imperialismo internacional del dinero.

Por la compra de los medios y de la publicidad, los poderes económicos no sólo amplían sus dominios en los planos financieros y mercantiles sino que también invaden la soberanía de los países huéspedes. Cuando estos países disminuyen o pierden su autosuficiencia económica también disminuyen o pierden su soberanía.

Uno de los efectos más funestos de la publicidad, que por todos los medios conduce al consumo, es la destrucción ecológica. La buena publicidad, dice el mercado, debe vender, debe crear la psicosis del consumo sin importar los medios y las consecuencias.

En las Cumbres de la tierra se enfatizan las agresiones a la madre tierra: derroche de recursos naturales, desertificación, deforestación, contaminación que produce un medio ambiente venenoso, calentamiento del planeta, descongelamiento de la costra de hielo de la Antártida y Groenlandia, entre otras gravísimas erosiones y ofensas.

Las soluciones a todos estos problemas (tal vez los más agudos que enfrenta la humanidad) son evidentes: el desarrollo sustentable, disminución de emisiones de gases que destruyen la capa de ozono, explotación racional de los recursos, reforestación y prohibición de la 
tala de árboles, retorno de los valores económicos a los valores de la vida, volver a entender el lenguaje del río y del viento, sentir y gozar la inmensidad del océano y la limpieza de las estrellas nocturnas; en suma, si no amar, respetar, a la tierra como madre y dejar de apreciarla como materia prima de explotación salvaje.

Las soluciones son claras y evidentes, pero todas se estrellan contra el muro inviolable del mercado, del capital, de las ganancias, de la manía de comprar y tener. La razón más humilde dice: por el bien de todos hay que detener la destrucción y disminuir el consumo, pero la publicidad dice: o consumo o muerte del sistema. Y hasta ahora la publicidad va ganando la batalla a la razón, se va imponiendo la irracionalidad destructiva.

El presidente W. Bush se niega a firmar el protocolo de Kyoto, porque reduciría las ganancias de sus industriales. El Sr. Bush presentó (22-VIII-2002) "un plan que permitirá aumentar la explotación de los bosques para reducir, según explicó, los incendios forestales". Qué bueno que las cadenas norteamericanas dieron tal noticia. De no ser así parecería una horrible calumnia contra el presidente; porque analícese la lógica del pensamiento: ¡Talar los árboles para evitar los incendios! Sin embargo, pronto apareció la verdad. "Se trata de un regalo para la industria maderera."

En este contexto ideológico es posible entender la contestación del mismo personaje cuando se le cuestionaba su actitud poco ética ante los problemas ecológicos: “¿Qué es más importante contestó, la ética o el bienestar de los norteamericanos?" Es explicable que no haya asistido a la Cumbre de la tierra de Johannesburg y que haya contagiado esta decisión a Canadá y Australia. Es muy posible que estos comportamientos, actitudes y razonamientos estén influyendo en las múltiples crisis de la nación, hasta ahora, hegemónica del mundo.

Las ofensas a la ética y al sentido común son incontables; sería provechoso un escrito de centenares de tomos que reuniera algunos de estos ejemplos. En todos aparecería la característica común: los valores de la vida son substituidos por los valores económicos. La publicidad impone con lo que vende toda una cosmovisión en la que teocentrismo 
y antropocentrismo son desplazados por el oro del becerro de oro en el comercio de Epicuro.

Con esta concepción sobre la vida se cae en la burla de la razón, de la sensibilidad estética, de la llamada dignidad, se cae en el peligroso absurdo. Sin olvidar que nuestra reflexión es sobre ética y publicidad daré sólo un ejemplo de esta dimensión del absurdo: Según Henri Lemaistre sólo en Francia se venden más de 100 millones de pantalones Jeans al año. Cerca de 70 millones han sido desgastados antes de ser vendidos. La demanda del consumidor se mueve así: comprar un pantalón que parezca viejo, usado, gastado, que recuerde al jean que el vaquero ha ensuciado y que seguirá usando sucio. (¡Qué emoción enfundarse un pantalón que ha usado y ensuciado el vaquero!)

"La evolución de la moda hoy nos empuja a los fabricantes a pasar del aspecto visual de gastado y sucio al efecto de una suavidad nunca antes lograda que se llama 'piel de durazno', producto del tallado hasta el desgarramiento con la piedra pómez.” (¡Combinación genial: prendas sucias, de vaqueros rudos pero con la suavidad de 'piel de durazno'!)

Hasta aquí todo suena exótico, caprichoso, irrisorio como tantos lujos y lujurias de la moda. Pero en la segunda parte de la historia del jean sucede la violación, el incesto en contra de la naturaleza: Para producir el efecto de sucio y deslavado se necesitan 60 litros de agua potable por pantalón (¡El agua debe ser limpia para producir el efecto de sucio!) Para el acabado del pantalón desgarrado se requieren 80 litros de agua y los ácidos para el despintado. Estas cantidades de agua por unidad deben multiplicarse por 70 millones que sólo en Francia se venden cada año.

Un inmenso torrente de agua, tan escasa y necesaria, para producir el efecto del pantalón vaquero emocionantemente sucio, desgastado o desgarrado en partes sugestivas. Pero además, el gran torrente corre como caudaloso río contaminado por las espumas corrompidas y los ácidos que aniquilan fauna y flora en su corriente mortal.

Si esta agresión a la sensatez, a la ecología es increíble, resulta más dramático aún que muchos millones de seres humanos sean manejados 
en forma tan degradante por las enormes manos de la publicidad que gobiernan caprichosa y burlonamente las marionetas en el mercado.

Me pregunto por qué los fabricantes, los mercaderes no emplean lodo, estiércol o deshechos putrefactos para producir el efecto de prendas sucias, de vaqueros sucios de estercoleros. También la publicidad se encargaría de venderlos. Así al menos no se desperdiciaría tanta agua preciosa, ni se sacrificarían tantas vidas por la contaminación producida.

Y este sólo es un ejemplo del absurdo y degradación que ha cultivado la sociedad mediática. Otro ejemplo, entre millones del mismo estilo y procedimiento publicitario del absurdo, es la manera infame en que se condicionan e inducen los votos para elegir como gobernantes a personas ineptas, a veces insensatas, a veces criminales. La publicidad que induce y condiciona los votos ha establecido el sistema único de la plutocracia como forma de gobierno. Sólo los ricos pueden pagar los costos de la manipulación electoral. Gravísima modalidad, por cierto, que ha llevado al poder a tantos dictadores peligrosos por el camino de la falsa democracia.

Una agresión más de la publicidad a la ética es su faz de inocencia, su apariencia de ingenuidad: ¿Qué tiene de malo que la rubia superior acompañe a una cerveza? ¿Qué tiene de irreverente la tierna oferta de la coca cola que mitiga la sed del recién nacido en el portal de Belén? ¿Qué ofensa puede imaginarse en que la dulce imagen del Papa obsequie el delicioso sabor de las Sabritas, de las que él mismo 'no puede comer sólo una'? ¿Qué daño causa el muy natural cuerpo casi desnudo de una mujer que invita a consumir un 'cuero' (el cinturón) que le sirve de cubierta? ¿Qué norma de justicia se viola al retirar el apoyo financiero a programas que denuncien violaciones y atropellos de 'gente importante' o al respaldar programas encubridores de infamias? 


\section{A modo de síntesis}

Todo en la publicidad aparece limpio, blanco, inofensivo, pero, como se ha visto, es un arma psicológica devastadora que abate toda resistencia individual o multitudinaria. Es el arma por excelencia del mercado, que con sus manos inmensas y poderosas convierte a la sociedad en dóciles títeres. Con sus 'satisfactores' indiferenciados a unos 'satisface' y a otros, casi a todos, los desgracia. Es la creadora de la eterna insatisfacción.

La publicidad es la provocadora del consumo insaciable, rápido y urgente y de los efectos correspondientes de destrucción ecológica. Es la más poderosa enemiga del desarrollo sustentable. Promete aceptación social a cambio de la obediencia ciega a una moda que humilla y que causa lástima por exótica y ridícula. Es generadora de odio y de violencia por la tensión de clases entre los de arriba, clientes que quieren y tienen, y los de abajo que quieren y no tienen.

La publicidad es el látigo implacable del imperialismo de las trasnacionales que elimina la competencia de los menos fuertes (casi todos). Impone monopolios y oligopolios globalizados. Destruye las soberanías de los países débiles (que son casi todos) al destrozar su fragilísima auto-subsistencia. Crea y aniquila visiones y valores de acuerdo al código imperativo de ventas y ganancias.

Y se ha llegado al extremo de convertir el juego de la política en un juego entre poderes publicitarios. Los candidatos, antes de pensar en sus ideas, ideales y proyectos sociales, antes de pensar en sus plataformas de campañas, investigan, en primera instancia, las mejores compañías de mercadotecnia y publicidad. Contratan a la mejor, no importa el precio, que sepa vender la imagen, los gestos y ademanes, que construya la personalidad más atractiva y arrolladora. El candidato se entrega a las manos y a la sensibilidad creadora del estilista, del masajista, del manicurista, del camarógrafo que deben producir la toma, el perfil, el look más impactantes. El candidato se entrega al mejor 
vendedor de la imagen que se convertirá en la mejor compradora de votos.

Esos hombres, tales hombres, los gobernantes triunfadores son los trofeos de las agencias publicitarias. La lucha entre las ideas y proyectos es light, la lucha entre las agencias es feroz.

Desde esta perspectiva es fácil contestar a la pregunta admirativa: ¿Cómo es posible que 'estos hombres' (sus nombres son abundantes) hayan podido llegar a la cumbre del poder? Allí yace la publicidad como la magia de la política, de la dominación, y los gigantes magos son, otra vez, las manos inmensas y poderosas que manejan los hilos, que determinan las elecciones. Así se consuma el apareamiento de la plutocracia (esta magia es muy costosa) con la mediocracia.

Parece superfluo comentar que existe, aunque muy escasa, una publicidad honesta: la que informa, la que publica con verdad los productos, sus características, usos riesgos y abusos. Sin embargo, es necesario decir que la publicidad reinante es agresora de la ética y de la dignidad humana, y que el único antídoto en contra de la dominación publicitaria es el fortalecimiento de la actitud crítica. En última instancia se trata de defender con energía el derecho a ser persona, a ser tratado como persona y no como instrumento de ganancia en el sistema mercantil que aprecia más al dinero que a las personas. 
CITAM Derechos Reservados.

La reproducción total o parcial de este artículo se podrá hacer si el ITAM otorga la autorización previamente por escrito. 